\title{
Leche humana y su efecto sobre la mineralización del esmalte: revisión de literatura
}

\author{
Human milk and its effect on enamel mineralization: a \\ literature review
}

\author{
Norma Leticia Robles-Bermeo ${ }^{1,2}$, Edith Lara-Carrillo²,Emma Herrera-Martínez ${ }^{3}$, Josué \\ Roberto Bermeo-Escalona ${ }^{4}$, Ana Miriam Santillán-Reyes ${ }^{5}$, América Patricia Pontigo-Loyola ${ }^{6}$, \\ Carlo Eduardo Medina-Solís ${ }^{2,6}$
}

\section{RESUMEN}

La leche materna es el alimento que provee al niño desde su nacimiento de todos los nutrientes que necesita para su crecimiento y desarrollo físico y psicológico. Su efecto sobre el tejido dental ha sido objeto de controversias, ya que se ha visto que actúa sobre la mineralización del esmalte y se ha asociado a caries de la infancia temprana. La leche humana tiene diversos componentes protectores para el esmalte dental pero al mismo tiempo contiene factores que pueden generar la pérdida de minerales. El propósito de esta revisión es exponer los elementos que producen la desmineralización y la remineralización del esmalte y proponer algunas medidas que apoyen la integridad de este tejido, así como recomendar la lactancia materna como la alimentación principal que el infante debe recibir durante el primer año de vida. La leche humana tiene diversas proteínas y elementos que ayudan en el proceso de desmineralización y remineralización del esmalte dental de la primera dentición. Se puede concluir que, la leche materna es el alimento ideal para los niños en los primeros años de vida. Por lo que hay que promover la lactancia materna como el método preferido para alimentar a los bebés. Se debe implementar la higiene desde que el primer diente erupciona en boca. Esta medida evitará que el posible efecto desmineralizante de la leche ejerza un efecto irreversible sobre el esmalte dental. Es conveniente orientar a las madres sobre el almacenamiento de la leche materna de tal manera que al ser consumida por el niño, no se encuentre acidificada, y

\begin{abstract}
Breast milk provides the child of all the nutrients he needs for his growth and physical and psychological development beginning at birth. Its effect on dental tissue has been the subject of controversy, since it has been seen to act on the mineralization of enamel and has been associated with early childhood caries. Human milk has various protective components for tooth enamel but at the same time it contains factors that can cause the loss of minerals. The purpose of this review is to review the elements that produce the demineralization and remineralization of enamel and propose some measures that support the integrity of this tissue, as well as to recommend breastfeeding as the main feeding source that the infant should receive during the first year of life. Human milk has various proteins and elements that help in the process of demineralization and remineralization of the tooth enamel of first dentition. It can be concluded that, breast milk is the ideal food for children during the first years of life. Therefore, breastfeeding should be promoted as the preferred method of feeding babies. Oral hygiene should be implemented as soon as the first tooth erupts. This measure will prevent the possible demineralizing effect of milk from exerting an irreversible effect on tooth enamel. It is advisable to guide mothers on the storage of breast milk so that when consumed by the child, it is not acidified, and does not produce harmful effects on the enamel.
\end{abstract}

\footnotetext{
${ }^{1}$ Programa de Doctorado de la Facultad de Ciencias de la Salud de la Universidad Anáhuac México. Ciudad de México, México.

${ }^{2}$ Centro de Investigación y Estudios Avanzados en Odontología "Dr. Keisaburo Miyata" de la Facultad de Odontología de la Universidad Autónoma del Estado de México. Toluca, México.

${ }^{3}$ Escuela de Biotecnología, Universidad Anáhuac México. Ciudad de México, Mexico.

${ }^{4}$ Escuela de Odontología, Universidad De La Salle Bajio. León, México

${ }^{5}$ Facultad de Odontología de la Universidad Autónoma del Estado de México. Toluca, México.

${ }^{6}$ Área Académica de Odontología del Instituto de Ciencias de la Salud de la Universidad Autónoma del Estado de Hidalgo. Pachuca, México. Correspondencia: Carlo Eduardo Medina-Solís Correo: cemedinas@yahoo.com

Conflicto de interés: Los autores declaran no poseer conflicto de interés

Recibido: 10/08/2019 Aceptado: 25/10/2019

Doi: https://doi.org/10.31698/ped.460320190010
}

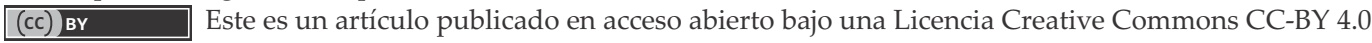


no produzca un efecto dañino sobre el esmalte.

Palabras clave: Leche humana; mineralización; esmalte; dentición primaria; salud bucal.

\section{INTRODUCCIÓN}

El inicio temprano de la lactancia materna, protege al recién nacido de infecciones y reduce la mortalidad neonatal. El riesgo de muerte por diarrea y otras infecciones puede aumentar en los lactantes que reciben alimentación exclusivamente artificial o lactancia materna parcial ${ }^{(1)}$. La leche materna (LM) es el mejor alimento que puede recibir el niño para tener un sano desarrollo. Algunos autores la consideran un factor de riesgo para el desarrollo de caries, mientras que otros reportan lo contrario ${ }^{(2-6)}$.

La dentición primaria inicia su erupción aproximadamente a los seis meses de edad, cuando idealmente los bebés son alimentados aún con LM. El esmalte está sometido a un ambiente donde se produce el proceso de desmineralización, que consiste en la pérdida de iones minerales de los cristales de hidroxiapatita. A la recuperación de estos iones se le conoce como remineralización, sobre todo cuando el ambiente favorece la ganancia mineral. Ambos procesos se presentan en la superficie dental y se puede perder una gran cantidad de minerales sin que se destruya la superficie del tejido, aunque con cambios en su color. Cuando se pierde la integridad del esmalte, se produce caries $^{(7)}$

El efecto de la LM sobre la mineralización del esmalte es de suma importancia, ya que puede ser el factor inicial que propicie o prevenga el desarrollo de la caries. En un estudio realizado en animales alimentados con leche humana, el esmalte desarrolló más lesiones de superficie lisa, comparados con otros a los que se les suministró leche de vaca $^{(2)}$. Se ha reportado asociación entre la duración de la lactancia por 18 meses o más con alta prevalencia de caries en niños japoneses ${ }^{(3)}$. Una revisión sistemática del tema ${ }^{(8)}$, donde la lactancia se extendió por más de un año, además de proporcionarse en las noches después de la erupción
Keywords: Human milk, mineralization, enamel, primary dentition, oral health.

dental, se asoció con caries de la infancia temprana, aunque es posible que la metodología empleada en los estudios y el control de factores como la higiene oral, la posible exposición al fluoruro, el contacto con azúcares y situación socioeconómica pudieran haber influido en los resultados.

El contenido de calcio y fósforo en la LM son elementos protectores que pueden ayudar a la mineralización del esmalte deciduo, asimismo, inmunoproteínas como la lactoferrina, que le confiere propiedades bacteriostáticas ${ }^{(9)}$. Ésta última posee demostrada actividad antibacteriana contra el Streptococcus mutans $^{(10)}$. Se han estudiado los péptidos bioactivos derivados de la leche, elementos que afectan el proceso biológico y pueden ser agentes preventivos de caries. Éstos provienen de una variedad de fuentes como el epitelio mamario o son producidos por células transportadas dentro de la leche; mientras que otros se extraen del suero materno y pasan a través del epitelio mamario acompañados de glóbulos de grasa, proteínas y lípidos desencadenando una secuencia fisicoquímica de eventos, con actividad anticariogénica, como inhibición bacteriana y aumento en la capacidad buffer salival, reduciendo la desmineralización del esmalte ${ }^{(11)}$. Existen otros componentes bioactivos como la lactoferrina, lisozima, lactoperoxidasa, factores de crecimiento y proteínas como las inmunoglobulinas que influyen también en el entorno bucal ${ }^{(6)}$.

Es importante conocer el efecto de la leche materna sobre el esmalte, no para desalentar la lactancia materna, sino para hacer las recomendaciones que permitan que el proceso sea saludable, tanto para la madre como para el bebé, asegurando el desarrollo óptimo de su dentición. 


\section{Características del esmalte primario}

La microestructura del esmalte está compuesta por prismas, dispuestas perpendicularmente de la unión dentina-esmalte a la superficie dental. El espacio interprismático es rico en proteínas y, en los dientes primarios, se ha descrito la presencia de una capa de esmalte aprismática delgada y uniforme. Algunas de las diferencias entre dientes primarios y permanentes son: el espesor del esmalte, que en dientes temporales va de 0.5 a $1 \mathrm{~mm}$, a diferencia de los dientes permanentes, donde mide de 1 a $2 \mathrm{~mm}$. El menor nivel de mineralización en dientes primarios, $80.6 \%$, comparado con los permanentes, de $89.7 \%$; la densidad numérica de los prismas es más alta en dientes deciduos, principalmente cerca de la unión amelodentinaria, y el mayor porcentaje de calcio y fósforo en dientes permanentes ${ }^{(12,13)}$.

Ópticamente, el esmalte de dientes primarios es más opaco, probablemente por mayor porosidad y clínicamente se observa que su desgaste es más rápido y que es menos resistente a la caries, lo que se ha comprobado en estudios in vitro. Las razones de su relativa menor mineralización pueden explicarse por su menor tiempo de maduración. Se ha demostrado que el periodo de formación de la corona de los dientes deciduos es muy corto, de aproximadamente un año, comprado con los dientes permanentes, que dura de 3 a 5 años ${ }^{(14)}$. Asimismo, el esmalte primario es más delgado que el permanente y su mineralización se lleva a cabo en menor tiempo. Este tiempo de mineralización sugiere que el esmalte oclusal, aunque de mayor grosor que el cervical, es más mineralizado, lo que se relaciona con el tiempo disponible más prolongado para la formación y maduración de la zona oclusal de la corona. Existen dos tipos de esmalte temporal, radial y en bandas de Hunter Scheger. Se ha observado que el radial tiene una mayor resistencia a la abrasión y registra valores más altos de microdureza Vickers. Éste se localiza en la parte externa del espesor adamantino y el esmalte en bandas se ubica en el interior, excepto en el área cervical. Las diferencias de microdureza entre estos dos tipos de esmalte se deben al ordenamiento de los prismas en cada una de las zonas, de manera que si el esmalte con bandas se expone a fuerzas masticatorias, se producirá mayor desgaste ${ }^{(15)}$. La permeabilidad del esmalte deciduo es mayor que en los permanentes, lo que sugiere mayor porosidad y posible hipomineralización. Estudios in vitro demuestran que la progresión de caries es significativamente más alta en el esmalte deciduo que en el permanente ${ }^{(14)}$.

\section{Proceso de desmineralización-remineralización del esmalte deciduo}

La caries dental es un problema de salud pública mundial ${ }^{(16)}$. La caries no tratada en la dentición primaria representa la 10ma condición más prevalente, afectando al $9 \%$ de la población mundial $^{(17)}$. En México, a los 6 años, la caries dental en la dentición primaria alcanza valores, de los índices de ceod, que van de 0.73 a 5.35 y prevalencias entre el $26.3 \%$ a $77.5 \%{ }^{(18)}$. Por lo que también en México se trata del principal problema de salud pública bucal, ya que tiene diversos impactos en las personas, familias y el sistema de salud ${ }^{(19-22)}$.

La caries es una enfermedad causada por al menos dos grupos de bacterias de los grupos Streptococo mutans y lactobacilos que producen ácidos como resultado de su metabolismo al fermentar los carbohidratos de la dieta, las caries o cavidades son el resultado de este proceso. Las bacterias son transmitidas por las madres (transmisión horizontal) o por los cuidadores (transmisión vertical) en épocas muy tempranas de la vida, incluso antes de la erupción dental. Así, cuando los dientes emergen en la cavidad bucal son colonizados y puede iniciarse el ciclo de destrucción ${ }^{(23)}$.

En condiciones naturales no es fácil distinguir los cambios iniciales que se producen en el esmalte; al principio solo se observan cambios a nivel microscópico, como resultado de la disolución periférica incompleta de los cristales, la pérdida de minerales es mínima y no excede más de $100 \mu \mathrm{m}$ de profundidad, después de 14 días se ha observado en un diente seco y bien iluminado cambios en la superficie externa del esmalte como resultado de la progresiva pérdida de minerales ${ }^{(24)}$.

Los cristales de hidroxiapatita forman los prismas del esmalte y entre ellos se encuentra el espacio interprismático que contiene agua y iones. Estos iones, de calcio $\left(\mathrm{Ca}^{+2}\right)$, fosfato $\left(\mathrm{PO}_{4}^{-3}\right)$ e hidroxilo $\left(\mathrm{OH}^{-}\right.$ ) están unidos por enlaces iónicos con fuertes cargas 
eléctricas opuestas y permiten un modelo altamente organizado. Cuando el esmalte, se encuentra en una solución subsaturada, es decir con una concentración de iones por debajo de la que se encuentra en el cristal, permite que la solución libere los iones del cristal en donde se encuentran en mayor concentración y se produce entonces el fenómeno de desmineralización. Por el contrario, cuando el medio externo tiene una mayor concentración de iones, se dice que es una solución sobresaturada y en tal caso, es el esmalte quien gana o recupera los iones sobre el cristal, dando lugar a la remineralización. En el esmalte dental, en condiciones normales de presencia de saliva y biopelícula, el proceso de intercambio iónico es permanente ${ }^{(15)}$. Cuando el proceso de desmineralización y remineralización pierde su equilibrio, por la producción bacteriana de ácidos provenientes del metabolismo de los carbohidratos, se inicia el proceso de caries $^{(23-25)}$. Las células del esmalte no son capaces de reparar o reconstruir el tejido después de que la mineralización se completa, sin embargo, es un tejido permeable y el intercambio iónico ocurre entre el esmalte y el medio externo ${ }^{(2,12)}$.

El balance en el proceso de desmineralización y remineralización hace la diferencia entre el desarrollo de caries y la conservación de la estructura y la salud dental. La desmineralización se lleva a cabo cuando se tiene un $\mathrm{pH}$ bajo (alrededor de 5.5), y el medio ambiente oral es bajo en saturación de iones minerales de calcio y fosfato, en relación al contenido mineral del diente. La estructura de los cristales del esmalte de hidroxiapatita carbonatada se disuelve por la presencia de ácidos orgánicos, como el láctico y acético, que son bioproductos resultado del metabolismo bacteriano, tomando como fuente para este metabolismo a los carbohidratos fermentables que provienen de la dieta ${ }^{(12,15)}$. Si se deja una porción de esmalte en agua por suficiente tiempo, los iones serán retirados uno a uno por las moléculas de agua, por lo que los cristales perderán iones hasta que se alcanza una concentración tan alta de éstos en el agua circundante que ya no se podrán seguir extrayendo iones de cristal Así se produce la salida de iones hacia el medio circundante y la pérdida de iones o desmineralización ${ }^{(12,15)}$. Es muy importante considerar que la desmineralización causada por una solución, como el agua o fuente de alimento, como la leche, en ausencia de microorganismos, es un factor trascendental a considerar en el desarrollo de caries dental ${ }^{(26,27)}$.

El proceso de desmineralización de un cristal se detiene cuando la solución está sobresaturada de iones y el proceso se dirige a la remineralización. Ésta se define como la ganancia de material calcificado (minerales) en la estructura dental, que reemplaza al que se había perdido previamente por desmineralización. En el esmalte en condiciones naturales con presencia de saliva y biopelícula este proceso es continuo, esto es, como resultado del metabolismo bacteriano se producen ácidos que liberan hidrogeniones $(\mathrm{H}+)$ y el $\mathrm{pH}$ bucal disminuye, este exceso de hidrógeno se une al fosfato y se forma ácido fosfórico. Por otro lado, los iones hidroxilo $(\mathrm{OH})$ también captan hidrógeno para formar agua, entonces las concentraciones de fosfato e hidroxilo libres disminuyen y se produce subsaturación en la solución o medio, en este caso bucal, favoreciendo la salida de iones minerales de hidroxiapatita del esmalte, produciendo la desmineralización. Si ésta continúa, se produce una lesión de caries. La saliva, evita por medio de los iones de bicarbonato, que captan el exceso de iones hidrógeno, la caída del pH bucal, cumpliendo con su función amortiguadora, así, con la menor concentración de iones hidrógeno, aumenta el valor del $\mathrm{pH}$ y los iones de fosfato e hidroxilo forman cristales, que están entonces disponibles para depositarse en el esmalte y permitir la remineralización. La hidroxiapatita del esmalte puede reemplazar los fosfatos por carbonatos, el calcio por sodio y los iones hidroxilos por fluoruro y producir apatitas de mayor complejidad, con propiedades físicas y químicas diferentes. Cuando se sustituyen los iones hidroxilo por fluoruro se generan cristales de fluorhidroxiapatita o fluorapatita, si se reemplazan uno o dos hidroxilos, que tienen mayor fuerza de atracción entre sus iones y son más difíciles de disociar en condiciones ácidas. Esto hace al esmalte más resistente a la desmineralización ${ }^{(15,24)}$. Cuando los iones de calcio y fosfato se recombinan formarán un cristal más fuerte y entonces se produce la remineralización. Este proceso se ve fortalecido si está presente el fluoruro que actúa como catalizador del proceso, de tal manera que éste puede detener o revertir el progreso de la caries y permitir al esmalte ser más resistente a la disolución ácida de lo que era originalmente ${ }^{(11)}$. 


\section{Factores remineralizantes de la leche humana}

La composición de la LM es dinámica, depende de la alimentación, etapa de lactancia, con diferencias entre madres y poblaciones. Las diferencias en la composición incluyen factores maternos, ambientales y la expresión y manejo de la leche (por ejemplo su almacenamiento y pasteurización). Después del nacimiento del bebé inicia la producción de leche, al principio en bajas cantidades, conocidas como calostro, rico en compuestos inmunológicos como la IgA, lactoferrina, leucocitos y factores de crecimiento epidérmico. El calostro contiene bajas concentraciones de lactosa, su función principal es inmunológica. Sus niveles de cloruro, sodio y magnesio son altos y son menores los de potasio y calcio en esta etapa, comparados con la leche que se produce posteriormente, denominada leche de transición, en la que también aumentan los niveles de lactosa. Los marcadores bioquímicos para el inicio de la lactancia por activación secretora incluyen el contenido de sodio, proporción sodio-potasio, citrato y lactosa ${ }^{(11)}$. La leche de transición tiene algunas de las características del calostro pero representa un periodo de incremento en la producción de leche, hecho que permite el crecimiento y nutrición del bebé. La leche es considerada completamente madura a las cuatro a seis semanas postparto, después de lo cual permanece similar en composición, aunque pueden ocurrir sutiles cambios en el transcurso de la lactancia ${ }^{(11)}$. Bajo estas condiciones, es posible afirmar que, por el periodo de la vida en el que tiene lugar la erupción dental, el esmalte de los dientes primarios estará expuesto al tipo de leche madura, secretada a partir del primer mes de vida del niño ${ }^{(28)}$.

La leche humana está compuesta de agua (88\%) permite al niño mantener equilibrio electrolítico, proteína en cantidades adecuadas $(0.9 \mathrm{~g} / 100 \mathrm{ml})$ para su crecimiento. Aunque más bajas que en el calostro y leche de transición, está compuesta en un $30 \%$ por caseína (casinato y fosfato de calcio) y $70 \%$ por proteínas del suero. Algunas de las proteínas del suero son: alfa-lactoalbúmina, seroalbúmina, betalactoglobulinas, inmunoglobulinas ( $\operatorname{Ig} A$ ), glicoproteínas, lactoferrina, lisozima, enzimas, moduladores de crecimiento, hormonas y prostaglandinas. La lisozima es una enzima muy abundante, tiene función antimicrobiana catalizando la ruptura de la pared celular de las bacterias y posee propiedades anti-inflamatorias, ${ }^{(6,28)}$ la mejor fuente de esta enzima es la leche humana. La lisozima junto con la lactoperoxidasa, actúan sinérgicamente e inhiben el metabolismo del $S$. mutans, reduciendo la producción de ácido en el medio bucal ${ }^{(6)}$.

La lactoferrina tiene acción bacteriostática contra $E$. Coli y S. Mutans, ${ }^{(6,2)}$ es capaz de vincular dos átomos de hierro y debido a que la leche humana predomina en estado no saturado en el intestino delgado del bebé, compite con las bacterias por el hierro. Así, microorganismos dependientes de este elemento no disponen de él para su proliferación y en sinergismo con la IgA secretora activan su acción bacteriostática. También puede tener efecto bactericida al actuar en las paredes de los microorganismos, causando su desestabilización y su muerte. Esta se encuentra elevada en el calostro y se mantiene, aunque en menores cantidades a lo largo de toda la lactancia ${ }^{(28,}$ ${ }^{29)}$. Tiene actividad contra bacterias Gram-negativas incluyendo el Streptococcus mutans ${ }^{(6)}$. También produce, durante su digestión, un péptido bactericida llamado lactoferricina, más potente que la misma lactoferrina, siendo activa contra Gram positivos y Gram negativos. Su potencial bactericida es mayor, por ser un péptido de menor tamaño, lo que facilita su acceso a sitios susceptibles de la superficie microbiana $^{(6)}$. La lisozima, la lactoferrina y la $\operatorname{IgA}$ se encuentran también en los elementos celulares de la leche materna como los macrófagos ${ }^{(28)}$.

Los componentes bioactivos que pueden tener relación con la prevención de caires dental necesitarían actuar contra las bacterias odontopatógenas o intervenir en el intercambio mineral en la superficie del esmalte. La prevención de caries por la acción de los péptidos bioactivos de la leche es una secuencia compleja de eventos físicoquímicos. Los péptidos bioactivos con acción anticaries tienen funciones preventivas múltiples, incluyendo la inhibición bacteriana, fortalecimiento de la superficie del esmalte, aumento de la capacidad buffer en la biopelícula, reducción de la desmineralización del esmalte. Se han llevado a cabo algunos estudios con fosfato de calcio o con caseinofosfopéptidos con la finalidad de actuar en el proceso de desmineralización y remineralización en 
el esmalte y evitar lesiones de caries, esto fundamentado en los componentes de la leche (fosfato de calcio y/o caseinofosfopéptidos), que se incorporan a la saliva y reducen la adherencia de microorganismos como el S. sobrinus y S. utans $^{(6)}$.

En lo que se refiere a la distribución de fluoruro en la leche humana, el suministro de este elemento al niño es muy bajo comparado con el que recibe de otras fuentes, en la leche materna solo se encuentra en niveles de traza ${ }^{(22,30)}$.

Posibles factores desmineralizantes de la leche humana

En un estudio realizado en animales que fueron alimentados con leche humana, se encontró que éstos desarrollaron significativamente más lesiones de superficie lisa que aquéllos que se alimentaron con leche de vaca, aunque en los surcos no hubo diferencia con el agua destilada. La explicación a esto puede ser que la leche humana contiene $7 \%$ de lactosa en comparación de $5 \%$ de la leche de vaca, además la leche de vaca contiene más calcio que la leche humana (114 contra $22 \mathrm{mg}$ ) y fósforo (96 contra $9.8 \mathrm{mg} / 100 \mathrm{~g})^{(2)}$.

Las menores concentraciones de minerales tienen un fundamento, el aporte total de minerales de la leche materna es bajo porque favorece el funcionamiento renal del lactante ya que le permite conservar el agua disponible para otras funciones como el control de la temperatura, sin eliminar orina ${ }^{(29)}$.

Se ha afirmado que la leche materna no causa disminución importante del $\mathrm{pH}$ de la placa y no ocasiona desmineralización del esmalte, a menos que se le agregue sacarosa ${ }^{(31)}$, sin embargo, hay estudios que reportan que la incubación de saliva con leche humana produce una caída importante del $\mathrm{pH}^{(2,32)}$ y que la exposición del esmalte a la biopelícula y leche materna produce más desmineralización del esmalte que la leche de vaca ${ }^{(2)}$.

El principal carbohidrato de la leche es la lactosa, disacárido compuesto de glucosa y galactosa, provee el $40 \%$ de energía para el lactante. La galactosa participa en la formación de galactolípidos necesarios para el sistema nervioso central. Aunque la madre tenga una dieta rica en carbohidratos la leche no tiene gran potencial cariogénico ${ }^{(5)}$. No obstante, se han reportado casos de caries de la infancia temprana en niños alimentados con leche materna y se ha afirmado que asumir que la leche materna es dentalmente segura no está completamente sustentado, pero la ausencia de estudios que lo comprueben ha permitido la controversia.

Teóricamente la leche humana tiene el potencial de producir caries debido a su alto nivel de lactosa, menor en la leche de vaca y a su bajo nivel de calcio y fósforo. Thomson realizó experimentos intraorales en los cuales confirmó el potencial de la leche humana para causar marcada desmineralización cuando está en contacto prolongado con el esmalte $^{(33)}$.

\section{Prácticas de lactancia relacionadas con el desarrollo de caries}

Aunque los beneficios para la salud de la lactancia materna son ampliamente reconocidos y bien documentados, las tasas de lactancia materna a nivel mundial en muchos casos no son óptimas. Además, las opiniones y recomendaciones están fuertemente divididas sobre la duración óptima de la lactancia materna exclusiva ${ }^{(34)}$. Desde 2001, la Organización Mundial de la Salud ha recomendado la lactancia materna exclusiva durante seis meses. Gran parte del debate reciente en los países desarrollados se ha centrado en la adecuación de micronutrientes, así como en la existencia y magnitud de los beneficios para la salud de esta práctica ${ }^{(35)}$.

La lactancia materna practicada durante 18 meses o más está asociada con alta prevalencia de caries. Después de ajustar con variables como sexo, frecuencia de cepillado, asistencia a revisión odontológica, bocadillos entre comidas, uso de fluoruro, tabaquismo materno durante el embarazo, exposición a humo de tabaco y niveles de educación de los padres, la asociación positiva permaneció significativa entre la duración de la lactancia materna y caries dental ${ }^{(3)}$. La Academia Americana de Odontología Pediátrica menciona que, la lactancia, provee los nutrientes necesarios para el crecimiento y desarrollo físico y psicológico del niño, disminuyendo el riesgo de contraer enfermedades. No la asocia epidemiológicamente con el desarrollo 
de caries, pero apunta que, la alimentación frecuente con biberón durante la noche y la lactancia materna pueden estar asociadas, aunque no consistentemente implicadas, con caries de la infancia temprana. Señala que la alimentación con seno materno más de siete veces al día después de los 12 meses de edad está asociada con el incremento en el riesgo de contraer éste tipo de caries $^{(36)}$. Se ha sugerido que la lactancia materna nocturna por más de un año está asociada a caries de la infancia temprana, sin embargo, por la importancia que tiene en la salud y desarrollo del niño y de la madre se requieren investigaciones rigurosas para afirmar que existe asociación entre lactancia y caries. Factores como la higiene dental, el control en el consumo de carbohidratos y la reducción de la colonización bacteriana permitirán reducir los niveles de caries de la infancia temprana ${ }^{(37-39)}$.

El efecto que pueda tener la LM sobre el tejido dental debe ser ampliamente estudiado, pero cualquiera que sea el resultado, no justifica de ningún modo dejar a un lado la lactancia materna porque sus beneficios son mucho mayores, tanto para el niño como para la madre. Es conocido y comprobado que la higiene es un factor fundamental para la salud dental por lo que será mejor implementar y fortalecer esta práctica al mismo tiempo que se recomienda la práctica de la lactancia. Por el contrario, el almacenamiento (congelamiento y descongelamiento), de la LM puede alterar las características de la misma. El pH de la leche humana es de 7.6 para el calostro, 7.44 para la leche de transición y 7.29 para la leche madura. La leche humana contiene fosfato y proteínas que le confieren capacidad buffer para los iones hidrógeno libres asociados a la gran cantidad de ácidos orgánicos presentes en la leche, así que estos valores de $\mathrm{pH}$ se mantienen hasta que son modificados por ácidos que tienen otro origen. El tiempo de duración del almacenamiento es proporcional a la caída del $\mathrm{pH}$ de la leche humana a cualquier temperatura, pero su caída es menor cuando la leche es congelada a $>19^{\circ} \mathrm{C}$. La modificación puede deberse a la lipólisis y liberación de ácidos grasos libres en la leche humana almacenada a temperaturas superiores a $\operatorname{los}-20^{\circ} \mathrm{C}$, por lo tanto, a mayor tiempo de almacenaje, mayor lipólisis y caída del $\mathrm{pH}$. Esto hace que, los dientes expuestos a leche humana almacenada sean más susceptibles a desmineralizarse $\mathrm{s}^{(40,41)}$.
El aumento de la capacidad buffer de la leche almacenada puede provocar una disminución importante del $\mathrm{pH}$, ya que los bicarbonatos salivales no son capaces de neutralizar la leche rápidamente, esto es más evidente cuando la leche es mantenida en refrigeración $\left(0^{\circ} \mathrm{C}\right.$ a $\left.4^{\circ} \mathrm{C}\right)$ por 8 días, mostrando una caída del $\mathrm{pH}$ y aumento de la capacidad buffer $^{(40)}$. En lo que se refiere al crecimiento bacteriano, la colonización de Streptococcus mutans aumenta proporcionalmente al periodo de almacenamiento y aumenta también conforme aumenta la temperatura del mismo. La pérdida de las propiedades antibacterianas de la leche almacenada puede deberse a la marcada pérdida de linfocitos viables y a la pérdida de las principales actividades bactericidas posterior a la refrigeración de la leche humana. La leche almacenada en refrigeración a una temperatura de $0^{\circ} \mathrm{C}$ a $4^{\circ} \mathrm{C}$ por 8 días o la refrigeración de leche descongelada puede ser la más cariogénica. Si se requiere almacenar la leche materna, la forma más segura para no afectar al esmalte es en el congelador a $-19^{\circ} \mathrm{C}$ hasta por dos semanas $^{(40,41)}$.

\section{CONCLUSIONES}

La LM es el alimento ideal para los niños en los primeros años de vida. Por lo que hay que promover la lactancia materna como el método preferido para alimentar a los bebés.

Se debe implementar la higiene desde que el primer diente erupciona en boca. Esta medida evitará que el posible efecto desmineralizante de la LM ejerza un efecto irreversible sobre el esmalte dental.

Es conveniente orientar a las madres sobre el almacenamiento de la leche materna y a su consumo no se encuentre acidificada y no produzca daño esmalte dental.

\section{AGRADECIMIENTOS}

Se agradece al Hospital Materno Perinatal "Mónica Pretelini Sáenz" (Toluca, Estado de México, México) las facilidades proporcionadas para el desarrollo de la investigación de campo, del que forma parte esta revisión. 


\section{REFERENCIAS BIBLIOGRÁFICAS}

1. Irala P, González V, Sánchez-Bernal S, Acosta J. Practicas alimentarias y factores asociados al estado nutricional de lactantes ingresados al Programa Alimentario Nutricional Integral en un servicio de salud. Pediatr. (Asunción). 2019; 46(2):82-89.

2. Bowen WH, Lawrence RA. Comparison of the cariogenicity of cola, honey, cow milk, human milk and sucrose. Pediatrics. 2005; 116(4):921-926.

3. Tanaka K, Miyake Y. Association between breastfeeding and dental caries in Japanese Children. J. Epidemiol. 2012; 22(1):72-77.

4. Weerheijm KL, Uyttendaele-Speybrouck BFM, Euwe HC, Groen HJ. Prolonged demand breas-feeding and nursing caries. Caries Research 1998; 32(1):46-50.

5. Rodriguez-Rodriguez MC, Pimentel EC. Puede la leche humana llegar a producir caries: Por qué y cómo? Acta Odontológica Venezolana [Internet]. 1998 [citado 15 May 2019]; 36:1. Disponible en: https://www.actaodontolo gica.com/ediciones/1998/1/art-5/

6. Aimutis WR. Bioactive properties of milk proteins with particular focus on cariogenesis. J Nutr. 2004; 134(4):989S995S.

7. Abou Neel E, Aljabo A, Strange A, Ibrahim S, Coathup M, Toung AM, et al. Demineralization-remineralization dynamics in teeth and bone. Int J Nanomedicine. 2016; 11:4743-4763.

8. Valaitis R, Hesch R, Pasarelli C, Sheenan D, Sinton J. A Systematic review of the relationship between breastfeeding and early childhood caries. Can J Public Health. 2000;91:411-417.

9. Christen L, Tat Lai C, Hartmann B, Hartmann PE, Geddes D. The effect of UV-C pasteurization on bacteriostatic properties and inmmunological proteins of donor human milk. PLOS one. 2013; 8(12):1-8.

10. Arnold R, Brewer M, Gauthier J. Bactericidal activity of human lactoferrin: sensitivity of a variety of microorganisms. Infect Inmun. 1980;28(3):893-896.

11. Ballard O, Marrow AL. Human milk composition: nutrients and bioactive factors. Pediatr Clin North Am. 2013; 60(1):49-74.

12. Sabel N. Enamel of primary teeth: morphological and chemical aspects. Swed Dent J Suppl. 2012; (222):1-77.

13. De Menezes Oliveira MA, Torres CP, Gomes-Silva JM,
Chinelatti MA, De Menezes FC, Palma-Dibb RG, et al. Microstructure and mineral composition of dental enamel of permanent and deciduous teeth. Microsc Res Tech. 2010; 73(5):572-577.

14. Wilson PR, Beynon. Mineralization differences between human deciduous and permanente enamel measured by quantitative microradiography. Arch Oral Biol. 1989; 34(2):85-88.

15. Tanevitch AM, Durso G, Batista S, Abal A, Llompart G, Llompart J, et al. Microestructura del esmalte en dientes deciduos: Los tipos de esmalte y la Resistencia a la abrasión. E-Universitas UNR Journal. 2013; 6(1):1713-1718.

16. Herrera MS, Medina-Solís CE, Robles-Bermeo NL, Minaya-Sánchez M, Alonso-Sánchez CC, Lara-Carrillo E, et al. Consulta por extracción dental en niños nicaragüenses: una aproximación a las necesidades de atención bucal. Pediatr (Asunción). 2017;44(3):239-244.

17. Marcenes W, Kassebaum NJ, Bernabé E, Flaxman A, Naghavi M, Lopez A, et al. Global burden of oral conditions in 1990-2010: a systematic analysis. J Dent Res. 2013;92(7):592-597.

18. Secretaría de Salud. Encuesta nacional de caries 2001. Secretaría de Salud. México DF; 2006.

19. Fernández-Barrera MA, Lara-Carrillo E, ScougallVilchis RJ, Pontigo-Loyola AP, Ávila-Burgos L, CasanovaRosado JF, et al. Study protocol of the cost-effectiveness comparison of two preventive methods in the incidence of caries: a randomized, controlled clinical trial. Medicine (Baltimore). 2019; 98(30):e16634.

20. Lucas-Rincón SE, Robles-Bermeo NL, Lara-Carrillo E, Scougall-Vilchis RJ, Pontigo-Loyola AP, Rueda-Ibarra V, et al. Interproximal caries lesions and premature loss of teeth in the primary dentition as risk factors for space loss in the posterior sector: a cross-sectional study. Medicine (Baltimore) 2019; 98(11):e14875.

21. Medina-Solís CE, Ávila-Burgos L, Márquez-Corona ML, Medina-Solís JJ, Lucas-Rincón SE, Borges-Yañez SA, et al. Out-of-pocket expenditures on dental care for schoolchildren aged 6 to 12 years: A cross-sectional estimate in a less-developed country setting. Int J Environ Res Public Health. 2019; 16(11):e1997.

22. Medina-Solís CE, Ávila-Burgos L, Borges-Yañez SA, Irigoyen-Camacho ME, Sánchez-Pérez L, Zepeda-Zepeda MA, et al. Needs and cost of treatment for dental caries in schoolchildren aged 6, 12 and 15 years: Data from a national survey in Mexico. Mexico: Universidad 
Autónoma del Estado de Hidalgo; 2019.

23. Featherstone JDB: Dental caries: a dynamic disease process. Aus Dent J. 2008; 53(3):286-291.

24. Bordoni N, Escobar A, Castillo Mercado R. Odontología Pediátrica. Argentina: Editorial Panamericana;2010.1200 p.

25. Rocha-Perez R, Coppi CL, Volpato CM, Groppo C, Aparecido-Cury J, Rosalen PL. Cariogenic potencial of cows, human and infant formula milks and effect of fluoride supplementation. Br J Nutr. 2009; 101(3):376-82.

26. Erickson PR, McClintock KL, LaFleur, J. Estimation of the caries-related risk associated with infant formulas. Pediatr Dent. 1998; 20(7):395-403.

27. Jensen ME. Actualización sobre desmineralización y remineralización [Internet]. Crest Oral-B; 2013. [citado 18 Set 2019] Unidades de Formación Continua. Disponible en: http://www.dentalcare.es/media/es-ES/education/ ce73/ce73_ES_131003.pdf

28. Shellhorn C, Valdés V. Manual de lactancia para profesionales de la Salud. Chile: UNICEF; 1995.

29. Macías SM, Rodríguez S, Ronayne de Ferrer PA. Leche materna: composición y factores condicionantes de la lactancia. Arch Argent Pediatr. 2006; 104(5):423-430.

30. Ekstrand J, Spak CJ, Falch J, Afsetch J, Ulvestad H. Distribution of fluoride to human breast milk following intake of high doses of fluoride. Caries Research. 1984; 18(1):93-95.

31. Flores-Concha P. Salivary $\mathrm{pH}$ level in children of 6 months of age with intake of evaporated milk modified and breast milk. Kiru. 2010; 7(1):17-24.

32. Bharath R, Bhavana VK, Neevan D'Souza, Shetty A, Vidya M, Hemanth $\mathrm{K}$. Enamel dissoluion of primary teeth in breast milk, bovine milk and infant milk formula.
Karnataka Paediatric Journal. 2012; 26(1):8-12.

33. Thomson ME, Thomson CW, Chandler NP. In vitro and Intra-oral investigations into the cariogenic potencial of human milk. Caries Research. 1996;30(3):434-438.

34. Jiménez Ortega AI, Velasco Rodríguez-Belvis M, Ruiz Herrero J, Peral Suárez Á, Martínez García RM, Bermejo López LM. Controversies and errors related to nutrition and breastfeeding: guidelines for improvement. Nutr Hosp. 2019; in press Doi: https://www.doi.org/10.20960/nh.02804

35. Kramer MS, Kakuma R. Optimal duration of exclusive breastfeeding. Cochrane Database Syst Rev. 2012; (8):CD003517.

36. American Academy of Pediatric Dentistry. Reference manual, recommendations: best practices. Pediatr Dent. 2016; 40:216-220.

37. Salone LR, Vann WF, Dee DL. Breastfeeding: an overview of oral and general health benefits. JADA. 2013; 144(2):143-151.

38. Hooley M, Skouteris H, Boganin C, Satur J, Kilpatrick N. Parental influence and the aged 0-6 years: A systematic review of the literature. J Dent. 2012; 40(11):873-885.

39. Nunes AMM, Alves CMC, Araujo FB, Ortiz TML, Ribeiro MRC, Silva AAM, et al. Association between prolonged breast-feeding and early childhood caries: a hierarchical approach. Community Dent Oral Epidemiol. 2012; 40(6):542-549.

40. Hegde AM, Vikyath R. Cariogenic potencial of stored human milk-an In Vitro Study. J Clin Pediatr Dent. 2007; 32(1):27-32.

41. Handa D, Ahrabi AF, Codipilly CN, Shah S, Ruff S, Potak D, et al. Do thawing and warming affect the integrity of human milk?. J Perinatol. 2014;34(11):863-866. 